\title{
The extinction of an e-health strategy
}

$\mathrm{T}$ he message, if not the theme, quickly became apparent: Admit defeat and move on.

Over and again, delegates to e-Health 2012: Innovating Health e-Care, Canada's annual gathering of e-health administrators, suppliers and users, were told that monolithic, centralized e-health databases are as outmoded as fax machines and other electronic devices which have long been supplanted by superior technologies and more efficient ways of doing things.

It's a bold new mobile world out there that is poised to revolutionize health care, Dr. John Hamalka, chief information officer of the Harvard [University] Medical School and the Beth Israel Deaconess Medical Center in Boston, Massachusetts, said in his keynote address to the gathering in Vancouver, British Columbia.

Grand, top-down e-health strategies are being eclipsed by "Facebook for health" concepts, Hamalka said, while arguing that it is up to clinicians and patients to use mobile technologies to connect "the doctor's brain to the patient's pain."

After sketching Harvard's decision to introduce electronic patient health records over a decade ago, create a network that allows full electronic access to health information and enables patients to schedule appointments and communicate with physicians electronically, Hamalka said it's become clear that "health care is no longer a providercentric world."

The cultural shift is enormous and the expectations placed on physicians have changed, he added, noting that doctors are now required to choose and purchase their own mobile devices. "There are 4900 devices on our network and I did not buy a single one of them."

Health technology administrators should follow Harvard's lead and simply refuse to follow the traditional paradigm of purchasing large information systems for hospitals and other health facilities through major-system procure-

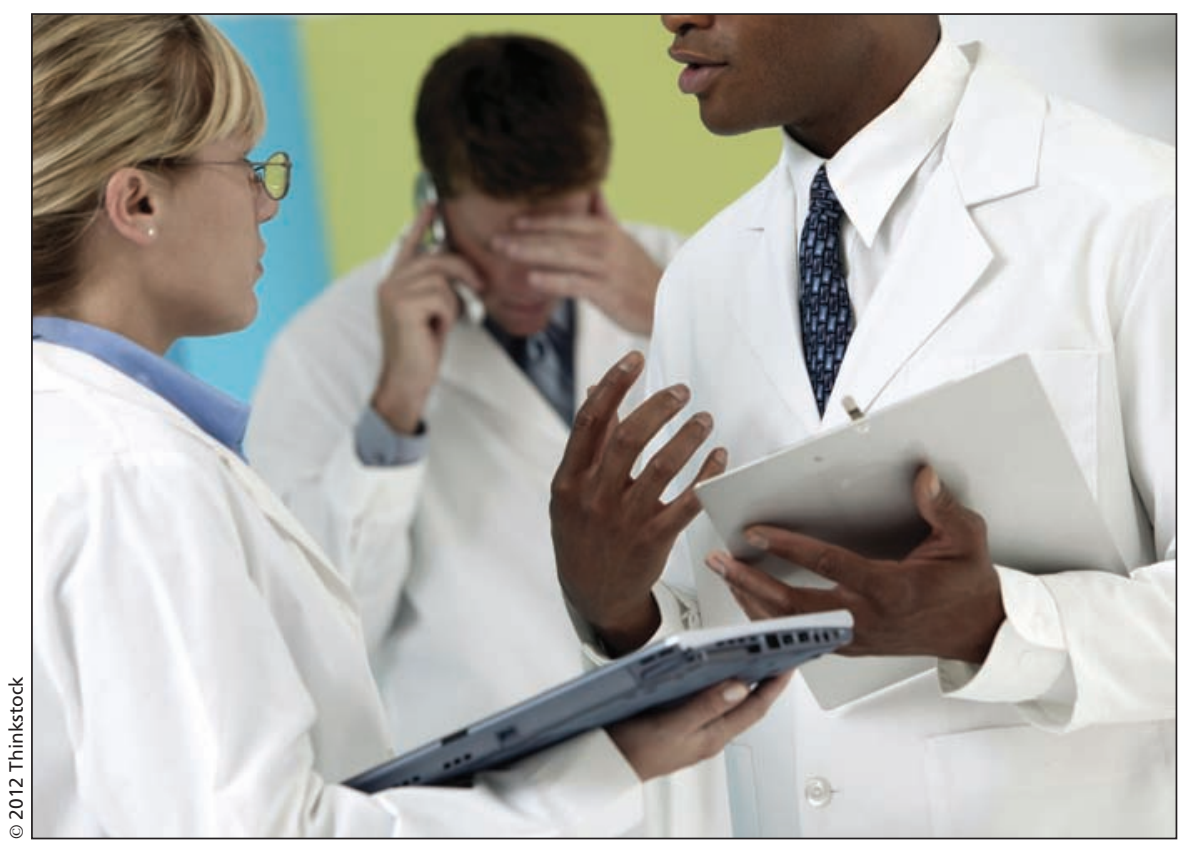

There is an increased expectation among health administrators and patients that doctors should utilize mobile technologies to make health care a less "provider-centric world."

ment contracts, Hamalka said. "Innovation is sometimes hard in a world of structured procurement, which is why we don't do it."

Rather, Hamalka urged that health technology officials refocus their investment on patient-centred innovations. "Your investments will be replaced by the edgy investors who take a risk. You want to take a risk with your current technology and try to leapfrog."

The notion that governments and hospitals could build major systems, as was unsuccessfully attempted in California, and then expect clinicians and patients to utilize them simply "didn't work," Hamalka argued. Part of the reason for this result was that clinicians resisted the additional work required by overlapping computer systems; "every time you give me another click to perform it adds an hour to my day."

The proposition that health care is in the midst of a mobile revolution resounded through sessions of the gathering. Online health communities are game-changing developments that will enable patients to better manage their own health, Sanjay Cherian, health industry lead for Accenture Canada, a management consulting, technology services and outsourcing company based in Toronto, Ontario, told a symposium on emerging health technology trends. "Smartphones are becoming medical devices."

"Technology is shifting power dynamics from providers to users," he said, adding that the unresolved issue is "who will pay."

Cherian and others at the gathering also argued that when governments attempt to act as catalysts for innovation, as Canadian Health Infoway did in pursuing an e-health strategy based on large health infostructure systems, they have often wound up funding obsolete systems and creating barriers that prevent technology change.

But while sketching eHealth Ontario's plans for at least seven large databases, Peter Bascom, vice president of architecture and standards for the $\$ 300$ million per year provincial eHealth Ontario, admitted that his agency's efforts to adapt to the new realities of patient-centred electronic care are "nascent." Bascom, 
though, indicated that Ontario is beginning to consider how to develop personal health records.

So too is Infoway, it appears.

Mobile technologies now widely used in the United States are "breaking medicine out of its cocoon," noted Dennis Giokas, chief technology officer for the federal agency, which has spent $\$ 2.1$ billion primarily on developing a national health infrastructure that lags well behind the efforts of Australia, New Zealand, the US and various European nations in achieving improvements in care through the use of electronic technologies.

"We need to change our mindset," Giokas said. "There will be no more monolithic system deployments." Asked why Infoway has invested so little in patient-focused innovations, Giokas insisted that "it's a false statement to say that we did not anticipate this."

But Canada's failure to implement e-health technologies at the clinicianpatient level is not strictly a function of inept e-health strategies, argued William Falk, fellow in residence at the Mowat
Centre for Policy Innovation at the University of Toronto and a leading contributor to Canada's first national e-health master plan. "We don't let most physicians in this country use the telephone, let alone emails," Falk observed with regard to the cluster of confidentiality, professional standards of care and clinical payment issues that have befuddled e-health in Canada while technology forges change in other nations. - Paul Christopher Webster, Vancouver, BC

CMAJ 2012. DOI:10.1503/cmaj.109-4221 